\title{
Non-destructive testing of layer-to-layer fusion of a 3D print using ultrahigh resolution optical coherence tomography
}

\author{
Israelsen, Niels Møller; Maria, Michael; Feuchter, Thomas; Podoleanu, Adrian; Bang, Ole
}

Published in:

Proceedings of SPIE

Link to article, DOI:

$10.1117 / 12.2269807$

Publication date:

2017

Document Version

Publisher's PDF, also known as Version of record

Link back to DTU Orbit

Citation (APA):

Israelsen, N. M., Maria, M., Feuchter, T., Podoleanu, A., \& Bang, O. (2017). Non-destructive testing of layer-tolayer fusion of a 3D print using ultrahigh resolution optical coherence tomography. In Proceedings of SPIE (Vol. 10329). [103290I ] SPIE - International Society for Optical Engineering. Proceedings of SPIE - The International Society for Optical Engineering https://doi.org/10.1117/12.2269807

\section{General rights}

Copyright and moral rights for the publications made accessible in the public portal are retained by the authors and/or other copyright owners and it is a condition of accessing publications that users recognise and abide by the legal requirements associated with these rights.

- Users may download and print one copy of any publication from the public portal for the purpose of private study or research.

- You may not further distribute the material or use it for any profit-making activity or commercial gain

- You may freely distribute the URL identifying the publication in the public portal 


\section{Non-destructive testing of layer-to- layer fusion of a 3D print using ultrahigh resolution optical coherence tomography}

Niels M. Israelsen

Michael Maria

Thomas Feuchter

Adrian Podoleanu

Ole Bang 


\title{
Non-destructive testing of layer-to-layer fusion of a 3D print using ultrahigh resolution optical coherence tomography
}

\author{
Niels M. Israelsen ${ }^{1 *}$, Michael Maria ${ }^{2,3}$, Thomas Feuchter ${ }^{2}$, Adrian Podoleanu ${ }^{3}$, \\ Ole Bang ${ }^{1}$ \\ ${ }^{1}$ DTU Fotonik, Department of Photonics Engineering, Technical University of Denmark, \\ DK-2800 Kgs. Lyngby, Denmark \\ ${ }^{2}$ NKT Photonics A/S, Blokken 84, 3460 Birkerød, Denmark \\ ${ }^{3}$ Applied Optics Group, University of Kent, Canterbury CT2 7NH, UK \\ *corresponding author electronic address: nikr@fotonik.dtu.dk
}

\begin{abstract}
Within the last decade, 3D printing has moved from a costly approach of building mechanical items to the present state-of-the-art phase where access to 3D printers is now common, both in industry and in private places. The plastic printers are the most common type of $3 \mathrm{D}$ printers providing prints that are light, robust and of lower cost.

The robustness of the structure printed is only maintained if each layer printed is properly fused to its previously printed layers. In situations where the printed component has to accomplish a key mechanical role there is a need to characterize its mechanical strength. This may only be revealed by in-depth testing in order to discover unwanted air-gaps in the structure.

Optical coherence tomography (OCT) is an in-depth imaging method, that is sensitive to variations in the refractive index and therefore can resolve with high resolution translucid samples.

We report on volume imaging of a 3D printed block made with 100\% PLA fill. By employing ultrahigh resolution OCT (UHR-OCT) we show that some parts of the PLA volume reveal highly scattering interfaces which likely correspond to transitions from one layer to another. In doing so, we document that UHR-OCT can act as a powerful tool that can be used in detecting fractures between layers stemming from insufficient fusion between printed structure layers. UHR-OCT can therefore serve as an useful assessment method of quality of 3D prints.
\end{abstract}

\section{INTRODUCTION}

The technology of 3D printing has evolved greatly during the past decade where prints scale from micrometer scale objects to macroscopic objects as large as houses. Progress in the 3D printing technology has made printers so affordable that they can now be purchased for in-home use. Most common are the layer-on-layer plastic printers which provide light, robust and lower cost prints $[1,2]$. Their widespread has allowed a diversity of

Optical Measurement Systems for Industrial Inspection X, edited by Peter Lehmann, Wolfgang Osten, Armando Albertazzi Gonçalves Jr., Proc. of SPIE Vol. 10329, 103290I · @ 2017 SPIE CCC code: $0277-786 X / 17 / \$ 18 \cdot$ doi: $10.1117 / 12.2269807$ 
mechanical solutions to demanding scientific experiments. Examples of wide diversity of their applications can be found in microfluidics [3], human tissue [4,5] and endoscopy [6].

When printing a structure, the robustness of the material is only maintained if each layer printed is properly fused to its neighboring layers. Even when using the same printer, identical printing design and settings, the performance in strength and strain of the component can vary significantly [7]. The robustness of the structure printed is only maintained if each layer printed is properly fused to its previously printed layers. In situations where the printed component has to accomplish a key mechanical role there is a need to characterize its mechanical strength. This may only be revealed by in-depth testing in order to discover unwanted air-gaps in the structure.

Optical coherence tomography (OCT) is an in-depth imaging method that can resolve with high resolution translucid samples, sensitive to variations in the refractive index [8]. In this work we demonstrate the power of ultrahigh resolution (UHR) - OCT for non-destructive testing (NDT) of faulty layer-to-layer print interfaces of a test print which cannot be otherwise detected by means of surface characterization.

The OCT system is schematically depicted in Fig. 1. The system is spectrometer based, using a supercontinuum source, SuperK Extreme from NKT Photonics, Denmark, as the light source. The source is bandpass filtered to provide light in the range of 1000-1500 nm only, roughly matching our spectrometer detection range. The light is guided to a 50/50 coupler and split into two paths, a sample arm (S) and a reference arm (R). Both rays entering $\mathrm{S}$ and $\mathrm{R}$ are collimated to a beam width of $3.4 \mathrm{~mm}$. In $\mathrm{S}$, two galvonometer mirrors are used to scan the beam in a raster pattern in the XY-plane of the sample. The beam is finally focused with a microscope objective. In $\mathrm{R}$ the beam travels through a dispersion compensation (DC) block and is finally reflected by a plane mirror. Reflected light from S and R mix in the coupler and the spectrum of the interfered signal is measured by a spectrometer from Wasatch Photonics, USA (1074-1078 nm with 2048 pixels). The spectrometer operates at a line rate of $76 \mathrm{kHz}$. An example of a measured interferogram is presented in Fig. 1, LHS.



Figure 1: Sketch of the experimental set-up.

To characterize the axial resolution as a function of optical path difference (OPD) the reference arm mirror was scanned within the imaging range of $2 \mathrm{~mm}$ with a mirror as sample reflector. In this way reflector peaks throughout the imaging range were found collectively representing the sensitivity roll-off. This characterization is seen in Fig. 2. By fitting Gaussian profiles to the post-processed data seen as reflector peaks, full-width-halfmaximum (FWHM) axial resolution was found as 3-5 $\mu \mathrm{m}$ within the imaging range. An increasing resolution was seen at larger OPDs. 


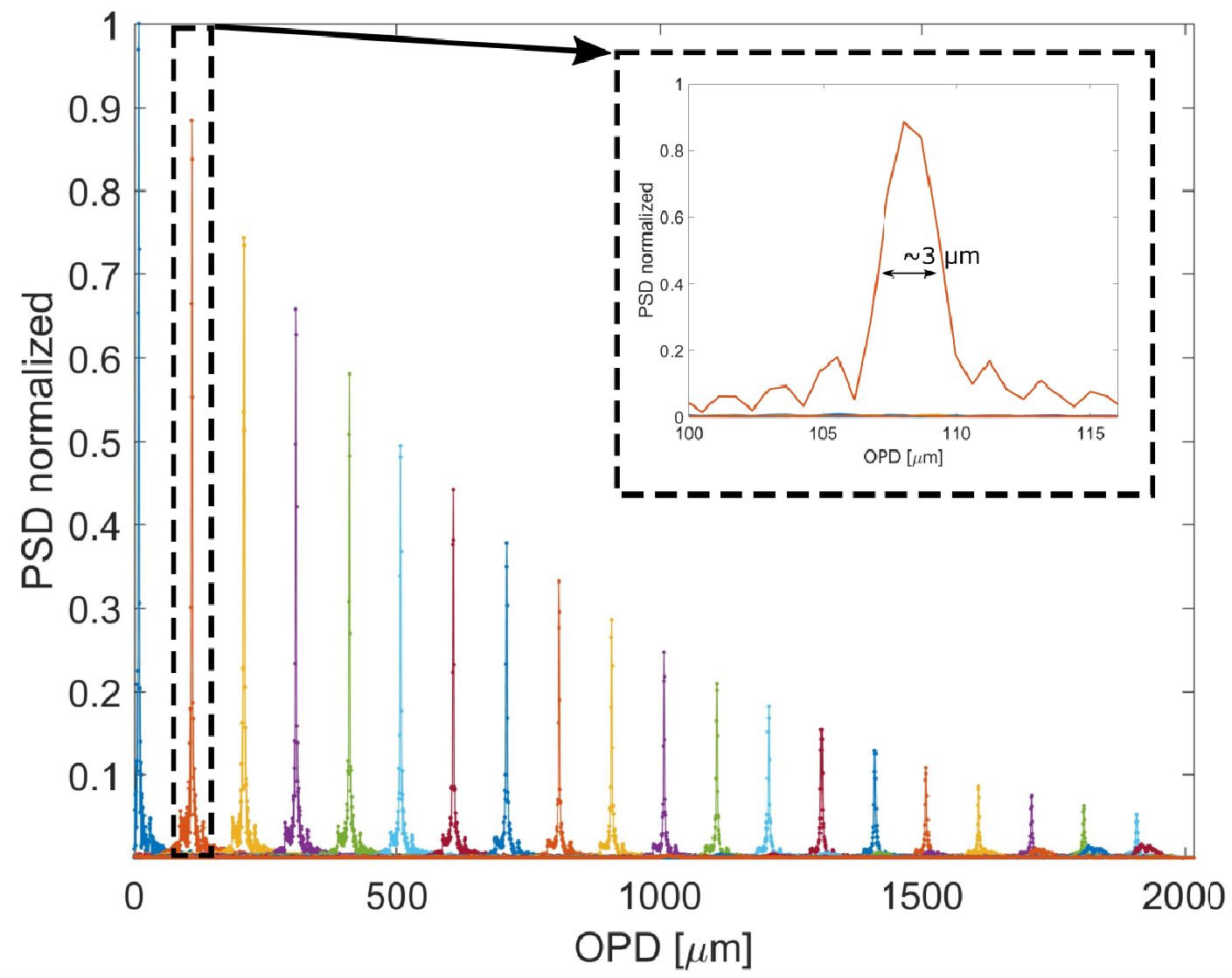

Figure 2: Axial resolution and sensitivity roll-off. Data was collected for different optical path differences adjusted by displacing the reference arm mirror whilst using another mirror as reflector in the sample arm. A zoom-in of the peak at OPD about $100 \mu \mathrm{m}$ is depicted in the inset.

The lateral resolution was characterized using a USAF target 1951 from Thorlabs. To build an en face image Ascans we performed in the XY plane of the sample generating a rectangular volume scan. From this the en face surface image of the target was extracted. An en face image of a subsection of the target is seen in Fig. 3.

Spacing between metallic bars could be recognized down to elements with bar width of $\sim 6 \mu \mathrm{m}$ in group 7 . 




Figure 3: En face image of a USAF target, 1951 to determine the lateral resolution. A part of group 6 and group 7 is seen in the image. Scale bar marks $80 \mu \mathrm{m}$.

The 3D printer used was an Ultimaker 2 from Ultimaker, The Netherlands, with a $0.4 \mathrm{~mm}$ nozzle hole size using polylactic acid (PLA) as printing material. The test sample is a $5 \mathrm{~mm} \times 50 \mathrm{~mm} \times 2 \mathrm{~mm}(\mathrm{~W} \times \mathrm{L} \times \mathrm{H})$ print with a layer height of $0.06 \mathrm{~mm}$ and $100 \%$ material fill, which means that we should expect no cavities or layer-to-layer divisions in bulk. The sample is seen in Fig. 4.

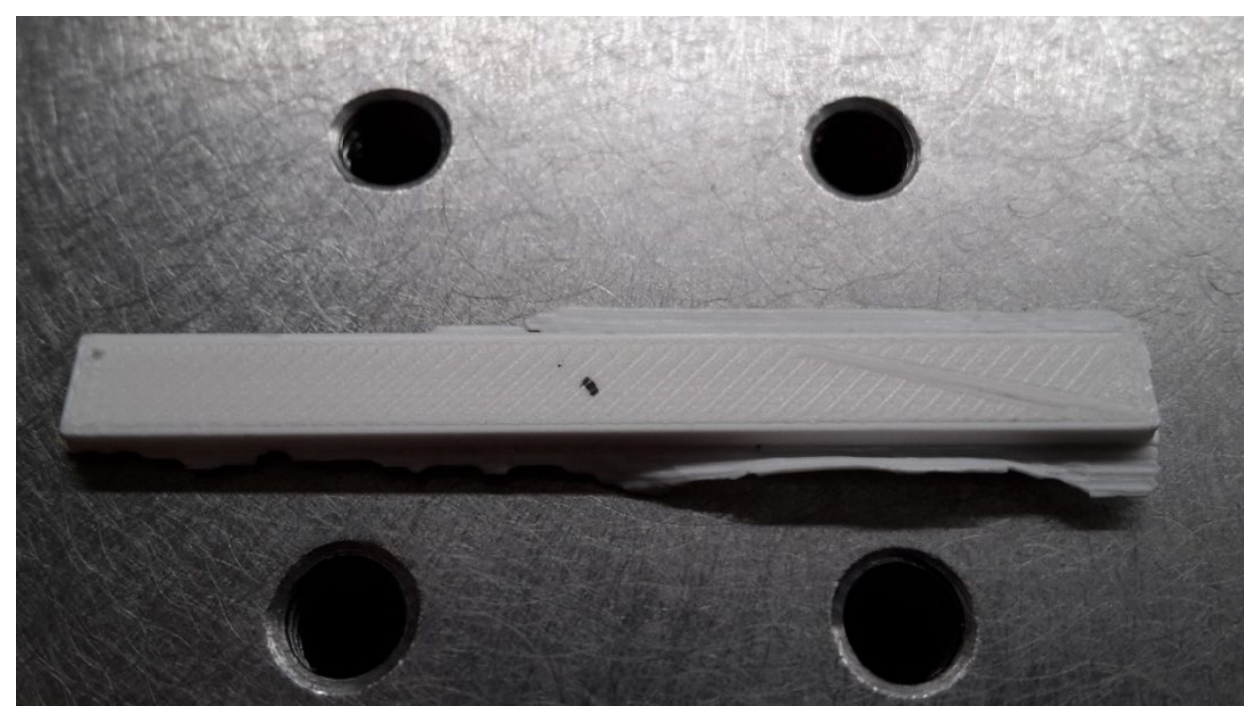

Figure 4: 3D printed PLA block for inspection. Dimensions are designed as $5 \mathrm{~mm} \times 50 \mathrm{~mm} \times 2 \mathrm{~mm}(\mathrm{~W} \times \mathrm{L} \times \mathrm{H})$. It has been marked with a black dot in the center for recognition. 




Figure 5: a) 3D printed test sample mounted for inspection, red circle pointing to the ROI. b) ROI reflection image of the far corner in XY plane seen in a), green rectangle marking the OCT scanning area. c1)-c10): OCT images recorded in steps of $6.25 \mu \mathrm{m}$ along $\mathrm{X}$. The white arrows indicate dislocation interfaces. d) A zoom-in of $\mathrm{c} 1$ ) with an arrow marking a highly reflecting interface. The inset is a reflection profile corresponding to the vertical blue line showing variation in material consistency.

The PLA sample was mounted on an XYZ stage with the sample surface about $7 \mathrm{~mm}$ away from the objective, as seen in Fig. 5, a). As a region of interest (ROI) of the sample, a corner in the XY plane was selected. By 
registering the largest spectrometer signal for a given $\mathrm{XY}$ position, a fast but primitive reflection image was built. This is seen in Fig. 5, b). In the ROI, a sub-area (green rectangle) was chosen where 10 B-scans (YZ) were recorded stepping X by $6.25 \mu \mathrm{m}$, depicted in Fig. 5,c1)-c10). In most of the images higher reflection "strings" are seen along the $\mathrm{Y}$ dimension (marked with white arrows) which we associate with insufficient fusion of two printed layers as marked with white arrows in Fig. 5, c1)-c10). The minimum distances we find between two scattering interfaces, which we define as single print layers, are seen to range between $70 \mu \mathrm{m}$ and $100 \mu \mathrm{m}$ in optical distance. This corresponds to $48 \mu \mathrm{m}$ and $69 \mu \mathrm{m}$, calculated using a refractive index of $n_{P L A}=1.45$ [9]. The layer height setting of $0.06 \mathrm{~mm}$ falls within this range. In Fig.5,d) a zoom-in of Fig. 5,c1) is provided highlighting the limited lateral extent of the sub-structure reflective interfaces.

In conclusion we report imaging of a 3D printed block made with 100\% PLA fill. By employing UHR-OCT we show that some parts of the PLA volume reveal higher scattering interfaces which likely correspond to transitions from one layer to another. In doing so, we document that UHR-OCT can act as a powerful tool to detect fractures between layers stemming from insufficient fusion between structure layers which can serve as an important characterization method. More work is required to connect the OCT results to the mechanical properties of the $3 \mathrm{D}$ prints.

\section{ACKNOWLEDGEMENTS}

This work was supported by the Technical University of Denmark Shape OCT programme, grant No. 410700011A and UBAPHODESA Marie Curie European Industrial Doctorate, grant No. 607627. A. Podoleanu also acknowledges the support of the NIHR Biomedical Research Centre at Moorfields Eye Hospital NHS

Foundation Trust and UCL Institute of Ophthalmology, Royal Society Wolfson Research Merit Award and ERC AMEFOCT grant No. 680879 .

\section{REFERENCES}

[1]: Berman, B., “3-D printing: The new industrial revolution”, Business horizons, 55(2), 155-162 (2012).

[2]: Pearce, J. M., "Building research equipment with free, open-source hardware", Science, 337(6100), 1303-1304 (2012).

[3]: Amin, R., Knowlton, S., Hart, A., Yenilmez, B., Ghaderinezhad, F., Katebifar, S., and Tasoglu, S., "3Dprinted microfluidic devices", Biofabrication, 8(2), 022001 (2016).

[4]: Corcoran, A., Muyo, G., van Hemert, J., Gorman, A., \& Harvey, A. R. "Application of a wide-field phantom eye for optical coherence tomography and reflectance imaging", Journal of modern optics, 62(21), 1828-1838 (2015).

[5]: Kim, H., Hau, N. T., Chae, Y. G., Lee, B. I., \& Kang, H. W., "3D printing-assisted fabrication of double-layered optical tissue phantoms for laser tattoo treatments", Lasers in surgery and medicine (2016). 
[6]: Sun, B., Nogami, H., Pen, Y., \& Sawada, R., "Microelectromagnetic actuator based on a 3D printing process for fiber scanner application”, Journal of Micromechanics and Microengineering, 25(7), 075014 (2015).

[7]: $\quad$ Tymrak, B. M., Kreiger, M., \& Pearce, J. M., "Mechanical properties of components fabricated with open-source 3-D printers under realistic environmental conditions", Materials \& Design, 58, 242-246 (2014)

[8]: Huang, D., Swanson, E. A., Lin, C. P., Schuman, J. S., Stinson, W. G., Chang, W., \& Fujimoto, J. G. , “Optical coherence tomography”, Science (New York, NY), 254(5035), 1178 (1991).

[9]: $\quad$ Bocchini, S., Fukushima, K., Blasio, A. D., Fina, A., Frache, A., \& Geobaldo, F., "Polylactic acid and polylactic acid-based nanocomposite photooxidation”, Biomacromolecules, 11(11), 2919-2926 (2010). 